\title{
Survey of Professional Skill Among Medical Residents of Tabriz University of Medical Science For Breaking Bad News
}

Bagher Matloubi-Sisi ${ }^{1}$, Abdolhossein Kazemi ${ }^{2}$, Zahra Mohammadzade-Vizhe ${ }^{3}$, Mohammad Zirak ${ }^{4}$, Mortaza Ghojazade $^{5}$, Mahasti Alizade ${ }^{6}$

1. Department of neurosurgery, Tabriz university of medical science, Tabriz, Iran

2. Bio-medical ethic fellowship, Tabriz university of medical science, Tabriz, Iran

3. department of anesthesiology, Tabriz university of medical science, Tabriz, Iran

4. Ph.D candidate of nursing, Tabriz university of medical science, Tabriz, Iran

5. Women's Reproductive Health Research Center, School of Medicine, Tabriz university of medical science, Tabriz, Iran

6. Department of Community Medicine, Tabriz university of medical science, Tabriz, Iran

\begin{abstract}
Lack of knowledge on scientific behaving with patients during giving bad news involves most of physicians even experienced physicians. Interestingly, this hurts physicians mind and in some cases causes sadness and depression or reaction on dealing with patient. In a cross sectional-descriptive study, 203 clinical assistant were included in study from 2009 to 2010 at Tabriz university of medical sciences. Comments of residents about giving bad news were registered on valid and reliable questionnaire. State of awareness by considering positive answers of statistical population were categorized into three groups; first group: weak awareness (true questions fewer than $50 \%$ ), second group: medium awareness (true questions between 50 to75\%), and third group: good awareness (true questions more than $75 \%$ ). Validity of questionnaire was assessed by evaluating contents and reliability using Cronbach's alpha. Stratified sampling was used based on academic year. Mean age of residents was $32.01 \pm 3.25$ years between the ranges of 26 to 43 years. Females were 76 individuals (37.4\%) and 127 individuals (62.6\%) males. Mean of physicians work experience was 2.1-2.9 (0-15 years range) at general period. Among residents, internal medicine residents agree on considering patients education before giving bad news much than other majors residents $(P=0.004)$. Mean score for residents' awareness about patients' right for knowing disease were $4.81 \pm 1.58(\min =0, \max =7)$; the mean for female residents was $4.9 \pm 1.49$ and $4.75 \pm 1.64$ for male residents. There is statistically significant differences between majors.

Present study, has shown that the knowledge of Tabriz University of Medical Sciences residents about breaking bad news are low. It seems that holding workshops about breaking bad news are necessary for educating medical students and residents.
\end{abstract}

Keywords: Breaking bad news; residents; knowledge; attitude;

\section{Introduction}

A question crosses minds of medical students when they starting to enter clinical

wards that it is an informing patient ant his/her relatives about illness; for example, how much information should be provided to patient and

\author{
Corresponding author: \\ Abdolhossein Kazemi \\ Bio-medical ethic fellowship, Tabriz university of medical science, Tabriz, Iran \\ Email: kazemi1338@gmail.com
}

Receive date: 2015-10-09 | Accept date: 2015-11-18 | Publish date: 2015-12-01

DOI: 10.7575/aiac.abcmed.16.04.01.06 
relatives in confronting with endstage cancer patient or who should inform the patient or relatives. Lack of knowledge on scientific behaving with patients during giving bad news involves most of physicians even experienced physicians. Interestingly, this hurts physicians mind and in some cases causes sadness and depression or reaction on dealing with patient (1).

Making logical relation between patient and physician and creating optimum mental conditions before giving bed news declines its destructive effects. In addition, it reduces patient stress and gives power to confront logically and responsibly with illness, treatment team, protocols, and necessary treatments (27).

Making emotional and human relation, giving professional and scientific information about disease simply, saying disease in a private and quiet condition, consciously dealing with common mechanisms of denial, and avoiding confusing patient were considered for giving bad news to patient (8-13).

Following the SPIKES strategy that include: setting up the interviews, assessing patient perception, obtaining patient invitation, giving knowledge and information to the patient, addressing the patient emotions with empathic reception, and strategy and summary were recommended in most of medical studies (14).

Normally, cases such as death of close relatives and diagnosed terminally illness behave like a shock. People panic by receiving news and all their life change suddenly. Almost, all women who have been got the news of breast cancer had anxiety and distress; this situation goes further on about $50 \%$ of patients and lead to severe mental disorders like depression. Isolation, crying, do not enjoy from enjoyable common actions, wish dying, aggression, long reticence, academic failure, attention deficit, forgetfulness, problem on making decision, Self-destructive thoughts, anger, sadness, sin, inability, disappointment, solitude, dizziness, fatigue and malaise, asthma, sigh, dry mouth, heart beat increase, numbness and heaviness, paresis, sense of tightness and suffocation in the throat, and stomachache can hurt patients and on most of cases it is hardship for people (15-16).

Informing patients from his/her illness and the severity are one of essential experiences that physicians must acquire on dealing with patients; even if patient is not able to hear that because during last moments of life, patients do not believe the news and are waiting for a miracle or giving life by physician (16-17).

It is not true to prohibit for giving proper information. Due to mourning, aging, illness, are part of life. Mourning is sadness and grief reaction to miss someone or even himself/herself (17).

Patients confront event by their own way. Patients and relatives should talk about their feels and tell their ideas in order to help better according to their bad news originated stress. In such cases, simple explanation without medical terms is effective (18). There are three models for conversation between physician and patients that includes Passive active pattern, help cooperation pattern, and mutual participation pattern (19-21).

The last one is complete treatment pattern. Therefore, best method for giving news is that inform patients about his/her illness then give more information based on patients knowledge and culture step by step (27).

\section{Material and methods}

In a cross sectional-descriptive study, 203 clinical assistant were included in study from 2009 to 2010 at Tabriz university of medical sciences. Comments of residents about giving bad news were registered on valid and reliable questionnaire. Questionnaire had two parts; 
the first part was about personal-social information and the second part was about residents' knowledge for giving bad news and their comments and point of view. Questionnaire was designed by referring to reference books, consultation with professors, and study of the scientific resources. State of awareness by considering positive answers of statistical population were categorized into three groups; first group: weak awareness (true questions fewer than 50\%), second group: medium awareness (true questions between 50 to $75 \%$ ), and third group: good awareness (true questions more than 75\%). One point was given to each true answer and zero to false and I do not know answers on scoring questionnaire. Validity of questionnaire was assessed by evaluating contents and reliability using Cronbach's alpha. Stratified sampling was used based on academic year. Data was analyzed using descriptive methods by SPSS 16 . Questionnaire was with coded by number without resident name.

\section{Results}

Mean age of residents was $32.01 \pm 3.25$ years between the ranges of 26 to 43 years. Females were 76 individuals (37.4\%) and 127 individuals $(62.6 \%)$ males. Mean of physicians work experience was 2.1-2.9 (0-15 years range) at general period. Residents with 2 years of experience before residency exam were 59 individuals (29.1\%) and 43 individuals (21.2\%) had 3 years of experience. Residents without prior experience were 26 individuals (12.8\%). Mean of residency years was $2.06 \pm 0.96$.

Residents with high agreement on evaluating patients knowledge before giving bad news were 106 individuals (52.3\%) and 42 (20.7\%) with very high agreement. 143 residents $(70.44 \%)$ had believed to consider patients education level before giving bad news. 129 residents (68.47\%) had believed to consider patients knowledge level before giving bad news. 143 residents (70.44\%) had believed to prepare patients mentally before giving bad news. 120 residents (59.11\%) had believed that it is better inform patients relatives to prevent great excitements during giving bad news to patient. Whereas, 33 residents (16.25\%) was contrary to that idea and they had believed to inform patient firstly. Among residents, internal medicine residents agree on considering patients education before giving bad news much than other majors residents $(X 2=87.79$, $d f=56, P=0.004)$.

Mean score for residents' awareness about patients' right for knowing disease were 4.81 \pm 1.58 ( $\min =0, \max =7$ ); the mean for female residents was $4.9 \pm 1.49$ and $4.75 \pm 1.64$ for male residents.

Score less than 4 was considered weak knowledge, 4-6 medium, and above 6 good. Among patients, 45 (22.3\%) of them had weak, 125 (61.9\%) individuals medium, and 32 $(15.8 \%)$ adequate knowledge.

Level of residents' awareness based on major was mentioned below: among internal medicine residents, 29 residents (64.4\%) had medium score, and 8 residents (17.7) had high score; among surgery residents, 11 residents (52.3\%) has low score, 7 residents (33.33\%) had medium, and 3 residents (14\%) had high score. There is statistically significant differences between various majors of residents. In response to question "If bad news has defined concept as physician for them or not?" 67 (33\%) residents had negative answer and 136 (67\%) had positive answer.

164 residents (80\%) believed that bad news with specific content are not bad for all people necessarily. 179 residents (88.2\%) believed that they must consider emotional condition of patients for ethics issues. 146 residents (71.9\%) believed that educational curses are necessary for learning of giving bad news. 137 residents (67.5\%) believed that an experienced team is a must have for giving bad news. 126 residents 
(62.1) agree on giving bad news in contrast to $37.9 \%$ resident which do not agree with the idea.

55 residents $(27.1 \%)$ give the mission of giving bad news to patients' family. On the other hand, 148 residents (72.9\%) consider it false. 178 residents $(87.7 \%)$ told that they had no academic education for giving bad news; only 44 residents $(21.7 \%)$ had studies about this issue. 181 residents considered it essential case that must take into account in academic educations.

\section{Discussion}

Informing patient about his/her illness and severity of it, is one of essential skills that physicians must acquire it when they visit patient. Asking about patients' knowledge about illness and process and giving new information step by step based on culture and knowledge is the best method (16).

Parle et al. has insisted on talking only physician with patient and giving proper information. Also, they consider evaluating patient knowledge before giving breaking bad news (17). Grassi et al. has demonstrated that revealing cancer disease is great issue among physicians. $45 \%$ of physicians has believed that patients should know facts about his/her illness. Whereas, $25 \%$ of them inform patients in fact; surgeons do this easier than other majors. The study recommends that family doctors should be educated theoretically and practically about giving bad news to cancer patients. In this way, specialist can refer their patients to their family doctor for explanations (18). Regg et al. considers creating relation with patient and describing illness as indisputable right for patients. Also, they recommend educating family doctors about giving bad news to cancer patients. So, specialist can refer the patient to family doctor for more explanation (18).

Present study, has shown that the knowledge of Tabriz University of Medical Sciences residents about breaking bad news are low. It seems that holding workshops about breaking bad news are necessary for educating medical students and residents.

\section{References}

1. Aein F, Delaram M. Giving bad news: a qualitative research exploration. Iran Red Crescent Med J 2014; 16(6):e8197.

2. Lioyd-Williams M, Lawrie I. Breaking bad news to patients and relatives. BMJ 2002; 325: 511.

3. Schildmann J, Cushing A, Doyal L, Vollmann J. Breaking bad news: experiences, views and difficultiesof preregistration house officers. Palliat Med 2005; 19(2):93-8.

4. Sample PL, Tomter H, Johns N. "The left hand does not know what the right hand is doing": rural and urban cultures of care for persons with traumatic brain injuries. Subst Use Misuse 2007; 42(4):705-27.

5. Agard A, Nilstun T, Lofmark R. Ethics in everyday care. The dialogue is physician's most important tool. Lakartidningen 2002; 99(19):2171-3.

6. Arnold R, Lidz CH. Clinical aspects of informed consent. In: Reich T, Ed. Enciclopedia of Bioethics. New York: MacMillan Library; 1995: 87.

7. Saukko PM, Ellard S, Richards SH, Shepherd MH, Campbell JL. Patients' understanding of genetic susceptibility testing in mainstream medicine: qualitative study on thrombophilia.BMC Health Serv Res 2007; 7:82.

8. Buckman R. How to break bad news? A guide for health care professionals. Maryland: The John Hopkins University Press; 1992: 123.

9. Goldfield N, Rothman WA. Ethical considerations of informed consent: a case study. Soc Sci Med. 1987; 24(6):4836.

10. Vegni E, Zannini L, Visioli S, Moja EA. Giving bad news: a GPs' narrative perspective. Support Care Cancer 2001; 9(5):390-6.

11. Chisholm CA, Pappas DJ, Sharp MC. Communicating bad news. Obstet Gynecol 1997; 90(4 Pt 1):637-9. 
12. Singer GR, Koch KA. Communicating with our patients: the goal of bioethics. J Fla Med Assoc 1997; 84(8):486-7.

13. Curtis JR, Engelberg RA, Wenrich MD, Shannon SE, Treece PD, Rubenfeld GD. Missed opportunities during family conferences about end-of-life care in the intensive care unit. Am J Respir Crit Care Med 2005; 171(8):844-9.

14. Angelos P, DaRosa DA, Derossis AM, Kim B. Medical ethics curriculum for surgical residents: results of a pilot project Surgery 1999; 126(4):701-5; discussion 705-7.

15. Wahlberg P. How to tell bad news? Lakartidningen1995; 92(16):1702-4.

16. Hoy AM. Breaking bad news to patients. Br J Hosp Med 1985; 34(2):96-9.

17. Ptacek JT, Eberhardt TL. Breaking bad news. A review of the literature. JAMA 1996; 276(6):496-502.

18. Bascunan ML. Truth disclosure in medicine: psychological perspective. Rev Med Chil 2005; 133(6):693- 8.

19. Farrell M, Ryan S, Langrick B. 'Breaking bad news' within a pediatrics setting: an evaluation report of a collaborative education workshop to support health professionals. J Adv Nurs 2001; 36(6):765-75.

20. Smith DH, McCarty K. Ethical issues in the care of cancer patients. Prim Care 1992; 19(4):821-33.

21. Turkoski BB. Ethics in the absence of truth. Home Health Nurse 2001; 19(4): 218-22, quiz 223.

22. Brewin T. Relating to the relatives. Breaking bad news, communication and support. New York: Radcliffe Medical Press, Cancer Medicine. Section 21: Pain and Palliation. Palliative Care; 1996: 77.

23. Andrew J. Perspectives in truth telling, etical issues. In: Reich T, Ed. Encyclopedia of Bioethics. New York: MacMillan Library, 1995:185.

24. Sullivan R, Menapace L, White R. Truth-telling and patient diagnoses. J Med Ethics 2001; 27: $192-7$.

25. Grantcharov TP, Reznick RK. Teaching procedural skills. BMJ. 2008 May 17;336(7653):1129- 31.

26. Rosner F. Informing the patient about a fatal disease: from paternalism to autonomy--the Jewish view. Cancer Invest 2004; 22(6):949-53.

27. Baile W, Buckman R, Lenzi R, Glober G, Beale E, Kudelka P. SPIKES-a six-step protocol for delivering bad news: application to the patient with cancer. Oncologist 2000; 5(4): 302-11. 